\title{
GESTÃO DO BLOCO CIRÚRGICO EM TEMPOS DE PANDEMIA: DE ONDE PARTIMOS E AONDE QUEREMOS CHEGAR
}

https://doi.org/10.5327/Z1414-4425202000030001

D esde o início da pandemia, a Agência Nacional de Vigilância Sanitária (ANVISA) recomenda que para todos os serviços de saúde seja elaborado e implementado um plano de contingência com estratégias e políticas necessárias para o enfrentamento da pandemia do SARSCoV-2, incluindo o gerenciamento dos recursos humanos e materiais ${ }^{1}$.

Esse plano deve definir as diversas ações práticas necessárias para o enfrentamento dessa situação de crise no serviço, entre as quais: vigilância e gestão de dados de pacientes e profissionais infectados; elaboração e implantação de protocolos clínicos e fluxos de trabalho (triagem de pacientes e profissionais suspeitos e infectados, afastamento e retorno laboral de profissionais que testaram positivo para COVID-19, entre outros); comunicação interna para todos os profissionais da instituição; capacitação e divulgação de protocolos, fluxos e uso adequado de equipamentos de proteção individual; monitoramento dos profissionais quanto à adesão às ações implementadas; monitoramento diário de suprimentos relacionados à pandemia; além de mecanismos que promovam a sensibilização de toda a equipe do serviço de saúde sobre ações que devem ser tomadas para o enfrentamento dessa pandemia ${ }^{1}$.

É importante que o serviço monitore periodicamente a implementação e a adesão às ações do plano de contingência, a fim de realizar os ajustes e as melhorias necessárias. O monitoramento do plano também favorece a detecção de pontos de melhoria, como, por exemplo, o reforço de orientações para determinado grupo de profissionais do hospital, a readequação de fluxos e ações emergenciais em casos de escassez de recursos materiais e humanos ${ }^{1}$.

Os grupos de profissionais que atuam no bloco operatório estão entre os mais afetados nos últimos meses pela pandemia da COVID-19, inicialmente com a suspensão de procedimentos eletivos e a priorização de cirurgias de urgência e emergência ${ }^{1}$. Além disso, em muitos hospitais, o centro cirúrgico tornou-se uma unidade de terapia intensiva preparada para receber pacientes contaminados, e as equipes de enfermagem e de médicos foram direcionadas para o atendimento a esses pacientes, otimizando a alocação de recursos e de espaço ${ }^{1}$. Se, em circunstâncias convencionais, realizar a gestão do bloco operatório já é uma missão desafiadora, repensemos esse cenário em tempos de maiores incertezas, mudanças, transições e pouco tempo para assimilações, remanejamentos de recursos e preparo da equipe para essa nova realidade ${ }^{2}$.

Nesses anos em que atuamos como gestoras de bloco operatório e participamos de frentes colaborativas no combate à pandemia, entendemos que a situação requer liderança, pensamento rápido, conhecimento prévio, confiança e ética, visibilidade, comunicação e poder de persuasão, flexibilidade e resiliência. Muitos líderes estão trabalhando remotamente e apoiando suas famílias, enquanto lidam com questões de assistência e segurança do paciente e da equipe multiprofissional ${ }^{3}$.

Aliados a esses fatores, fazem parte do escopo da função da liderança atual do bloco operatório redesenhar os modelos de assistência e de capacitação da equipe em tempo real, desenvolver cursos intensivos em enfermagem em terapia intensiva, transformar completamente o ambiente cirúrgico em leitos de terapia intensiva e retorná-los para a retomada de cirurgias, voltando novamente aos modelos de planejamento habituais ${ }^{3}$.

Alguns comportamentos de liderança tornam-se essenciais nessa situação de crise, como:

- decidir com velocidade e precisão, identificando os pontos mais importantes a ser trabalhados e engajando as lideranças;

- adaptar-se com ousadia, decidindo o que não fazer e ajustando-se ao novo;

- realizar entrega confiável, alinhando o foco da equipe e monitorando o desempenho; 
- envolver-se com o cuidado da própria equipe, motivando-a e comunicando clara e completamente novas metas e informações importantes ${ }^{3}$.

Atualmente vivenciamos uma gradual recuperação do volume cirúrgico, em meio a esforços concentrados para proteger pacientes e funcionários e aliviar os receios sobre a exposição ao vírus. Algumas recomendações são essenciais para que os riscos não se sobreponham às necessidades individuais. Qualquer retomada deve ser autorizada pelas autoridades municipais e estaduais de saúde, pelo Sistema Único de Saúde (SUS), e devem ser avaliadas as decisões locais das operadoras de saúde (Sistema Suplementar, pela Agência Nacional de Saúde - ANS) e das instituições de saúde ${ }^{1,4,5}$.

Paralelamente à retomada de cirurgias eletivas, em 19 de junho de 2020, o Ministério da Saúde publicou no Diário Oficial da União a Portaria $n^{\circ} 1.565$, que estabelece orientações gerais sobre a prevenção, o controle e a mitigação da transmissão do coronavírus. As orientações também são voltadas à promoção da saúde física e mental da população. O objetivo é apoiar as estratégias locais para a retomada segura das atividades e do convívio social, respeitando as especificidades e as características de cada setor ou ramo de atividade. Caberá às autoridades locais e aos órgãos de saúde locais decidir, após avaliação do cenário epidemiológico e da capacidade de resposta da rede de atenção à saúde, a retomada das atividades.

Tratando-se de retorno de cirurgia eletiva, diante de uma infecção pandêmica, precauções ostensivas foram implementadas e vêm sendo monitoradas de forma constante e por um período de tempo indeterminado, como: monitoramento de acessos, distanciamento social nos ambientes hospitalares, uso de equipamentos de proteção específicos, rotinas e protocolos de descontaminação, condutas específicas em procedimentos com geração de aerossóis, diminuição de pessoas circulando e otimização em sala de cirurgia, fluxos seguros sem cruzamento dos pacientes infectados, além do controle ambiental com pressão negativa/neutra e troca de ar para as cirurgias de pacientes suspeitos ou contaminados e pressão positiva em sala operatória com paciente de cirurgia eletiva não contaminado ${ }^{1,4,5}$.

Toda essa nova situação trouxe à tona novas práticas que devem ser consideradas como o novo normal no ambiente hospitalar, principalmente nos setores onde ocorre grande manipulação das vias aéreas e fluidos corporais dos pacientes. Há que se assegurar que os profissionais que participarão desses atendimentos tenham o treinamento adequado sobre essas técnicas de precaução. A utilização de novas ferramentas, como telemedicina e reuniões por plataforma a distância, tornou-se habitual e necessária ${ }^{6,7}$.

É importante que os líderes da organização mantenham a infraestrutura crítica e, ao mesmo tempo, forneçam suporte aos membros da equipe e sejam empáticos com as suas necessidades. No ano internacional da enfermagem, cabe a nós, profissionais dessa área, dessa linda profissão de quase 200 anos, nos orgulharmos a cada dia e honrar o legado deixado por Florence Nightingale, que contempla força, coragem e dedicação, atitudes nobres que nos fazem ímpares nessa missão do cuidado ao próximo.

Giovana Abrahão de Araújo Moriya $(1$ Doutora em Enfermagem pela Escola de Enfermagem da Universidade de São Paulo (USP), São Paulo, Brasil. Supervisora do Centro Cirúrgico do Sabará Hospital Infantil, São Paulo, Brasil. Presidente da Associação Brasileira de Enfermeiros de Centro Cirúrgico, Recuperação Anestésica e Centro de Material e Esterilização (SOBECC).

Márcia Cristina de Oliveira Pereira (1) Mestre em Enfermagem pela Escola de Enfermagem da USP, São Paulo, Brasil. Gerente do Bloco Cirúrgico do Hospital Beneficência Portuguesa, São Paulo, Brasil. Vice-presidente da SOBECC.

\section{REFERÊNCIAS}

1. Brasil. Ministério da Saúde. Agência Nacional de Vigilância Sanitária. Nota Técnica GVIMS/GGTES/ANVISA n 06/2020. Orientações para a prevenção e o controle das infecções pelo novo coronavírus (Sars-CoV-2) em procedimentos cirúrgicos. Brasil: Ministério da Saúde; 2020.
2. Brasil. Ministério da Saúde. Agência Nacional de Vigilância Sanitária. Nota técnica GVIMS/GGTES/Anvisa nº 07/2020. Orientações para prevenção e vigilância epidemiológica das infecções por SarsCoV-2 (Covid-19) dentro dos serviços de saúde. Brasil: Ministério da Saúde; 2020. 
3. NicholsC, HaydenSC, TrendlerC.4behaviors thathelpleadersmanageacrisis. Harv Bus Rev [Internet]. 2020 [acessado em 22 ago. 2020];4. Disponível em: https://hbr.org/2020/04/4-behaviors-that-help-leaders-manage-a-crisis

4. Associação Brasileira de Enfermeiros em Centro Cirúrgico, Recuperação Anestésica e Centro de Material e Esterilização (SOBECC). Recomendações relacionadas ao fluxo de atendimento para pacientes com suspeita ou infecção confirmada pelo COVID-19 em procedimentos cirúrgicos ou endoscópicos [Internet]. São Paulo: SOBECC, 2020 [acessado em $1^{\circ}$ ago. 2020]. Disponivel em: http:// sobecc.org.br/arquivos/RECOMENDACOES_COVID_-19_SOBECC_ MARCO_20201.pdf

5. World Health Organization. Statement on the second meeting of the International Health Regulations (2005) Emergency Committee regarding the outbreak of novel coronavirus (2019nCoV) [Internet]. World Health Organization; 2020 [acessado em $1{ }^{\circ}$ abr. 2020]. Disponível em: https://www.who.int/ news-room/detail/30-01-2020-statement-on-the-second-meetingof-the-international-health-regulations-(2005)-emergency-committeeregarding-the-outbreak-of-novel-coronavirus-(2019-ncov)

6. Tao KX, Zhang BX, Zhang P, Zhu P, Wang GB, Chen XP. Recommendations for general surgery clinical practice in novel coronavirus pneumonia situation. Zhonghua Wai Ke Za Zhi. 2020;58(3):170-7. http://doi. org/10.3760/cma.j.issn.0529-5815.2020.0001

7. Brasil. Ministério da Saúde. Agência Nacional de Vigilância Sanitária. Nota Técnica GVIMS/GGTES/ANVISA nº 04/2020. Orientações para serviços de saúde: medidas de prevenção e controle que devem ser adotadas durante a assistência aos casos suspeitos ou confirmados de infecção pelo novo coronavírus (Sars-CoV-2) [Internet]. Brasília: Ministério da Saúde; 2020 [acessado em 22 ago. 2020]. Disponivel em: http://portal.anvisa.gov.br/documents/33852/271858/ Nota+T\%C3\%A9cnica+n+04-2020+GVIMS-GGTES-ANVISA/ ab598660-3de4-4f14-8ebf-b9341c196b28 